\title{
Vigilancia tecnológica e inteligencia competitiva para la producción de tilapia roja (Oreochromis mossambicus) en el departamento del Huila, Colombia
}

\section{Technology watch and competitive intelligence for the production of red tilapia (Oreochromis mossambicus) in the department of Huila, Colombia}

\section{Guillermo Camero-Escobar ${ }^{1}$ Hugo Calderón-Calderón ${ }^{2}$}

Recibido: febrero 06 de 2018 Aceptado: junio 28 de 2018

\section{Resumen}

El artículo presenta los resultados de un estudio de vigilancia tecnológica e inteligencia competitiva sobre la producción de tilapia roja (Oreochromis mossambicus), en el Departamento del Huila, Colombia. La investigación es cualitativa, descriptiva, no experimental y la toma de datos fue transversal. Los factores críticos de vigilancia corresponden al eslabón de cultivo de la tilapia, como: insumos, sistemas de producción y producción de semillas, entre otros. Los hallazgos indican que la tendencia investigativa se ha enfocado en la búsqueda de una calidad estandarizada de los elementos fisicoquímicos. Los temas fundamentales se orientan hacia la dieta alimenticia para obtener alto contenido proteico, las densidades de siembra y evaluación del desempeño de crecimiento. En menor proporción se han adelantado investigaciones sobre mejoramiento genético y un campo que se empieza a explorar es el relacionado con subproductos de tilapia roja. En cuanto al Huila, se concluye la necesidad de implementar estrategias que permitan a los productores apropiarse de los avances reportados en artículos y patentes, de modo que los empresarios puedan tomar decisiones informadas para mejorar la competitividad del sector.

Palabras clave: vigilancia tecnológica, inteligencia competitiva, tilapia roja, factores críticos de vigilancia, productividad piscícola.

\section{Abstract}

This article shows the results of a technological surveillance and competitive intelligence study about the production of red tilapia (Oreochromis mossambicus), in the Department of Huila, Colombia. The research is qualitative, descriptive and not experimental and the data collection was transversal. The critical monitoring factors correspond to the tilapia culture link, such as: inputs, production systems and seed production, among others. The findings indicate that the research trend has focused on the search for a standardized quality of the physicochemical elements. The basic issues are oriented towards the diet to obtain high protein content, planting densities and evaluation of growth performance. To a lesser extent, research on genetic improvement has been carried out and a field that is beginning to be explored is related to red tilapia byproducts. Regarding the Department of Huila, it is concluded the need to implement strategies that allow producers to appropriate the advances reported in articles and patents, so that employers can make informed decisions to improve the competitiveness of the sector.

Keywords: technology surveillance, competitive intelligence, red tilapia, critical monitoring factors, fish productivity.

1 Administrador de Empresas, Magíster en Administración de Organizaciones, Universidad Nacional Abierta y a Distancia, La Plata, Colombia. E-mail: guillermo.camero@unad.edu.co

2 Ingeniero Industrial, Magíster en Administración de Organizaciones, Corporación Universitaria del Huila, Neiva, Colombia. E-mail: hugo.calderon@corhuila.edu.co 


\section{Introducción}

De acuerdo con la Organización de las Naciones Unidas para la Alimentación y la Agricultura, FAO por sus siglas en inglés, en los últimos años se observa una notable disminución de la pesca de captura en el mundo, conduciendo a que la producción acuícola controlada se constituya en una fuente alternativa de proteína para la seguridad alimentaria mundial, y a su vez como una actividad generadora de empleo e ingresos (FAO, 2014).

La piscicultura, definida como aquella actividad dedicada al cultivo de peces bajo manejo e implementación de buenas prácticas, a saber: desarrollo genético, incubación, alimentación, reproducción y sanidad de las especies, ha crecido de manera considerable durante las últimas décadas (Montes-Hincapié et al., 2017). De hecho, la FAO señala que en los últimos 20 años la producción mundial de especies como: tilapia, trucha y cachama, han crecido a ritmos de 12,6 y $29 \%$, respectivamente (FAO, 2014).

La tilapia roja se Obtuvo de múltiples cruces entre varias especies de tilapia, a saber: Oreochromis mossambicus, Oreochromis niloticus, Oreochromis aureus y Orochromis hornorum. Su coloración la hace similar a especies como el pargo rojo y la percha, lo que estimuló a productores e investigadores a iniciar un acelerado programa de hibridación, permitiendo la obtención de nuevas líneas de tilapia roja (Campo, 2003). Sin embargo, a diferencia de otras especies, la tilapia roja demanda atenciones técnicas considerables en su proceso de cultivo. Por ejemplo, requiere ambientes con temperatura entre los 24 y $30^{\circ} \mathrm{C}$, alimentación con balanceado comercial, y protección especial en todas las etapas, por cuanto es vulnerable a la predación, dado que carece de mimetismo natural (Amado, Córdoba-Rojas \& Barbosa, 2015).

El Ministerio de Agricultura y Desarrollo Rural (2007), ha señalado que el incremento permanente de la producción mundial de tilapia, desde la década de los ochenta, evidencia la importan- cia que ha tomado este grupo de especies a nivel mundial; se conocen en la actualidad por lo menos 60 especies diferentes de tilapia, de las cuales 10 son utilizadas para el consumo humano. En Colombia, como incentivo a este crecimiento, se reconoce la política de la FAO en cuanto al cultivo de tilapia como una estrategia para la seguridad alimentaria.

Estados Unidos se ha convertido en el principal destino para las exportaciones de productos provenientes de la agroindustria colombiana (Trochez-Gonzalez, Valencia \& Salazar-Uribe, 2018; Vásquez-Barajas, García-Torres, Bastos-Osorio \& Lázaro-Pacheco, 2018). En el caso de la tilapia, este esfuerzo se ha visto reflejado en el crecimiento en las cantidades exportadas que se vienen presentando desde el 2004. A nivel nacional la producción de los filetes se encuentra concentrada en el departamento del Huila, donde varias empresas han desarrollado la infraestructura y logística necesaria para la producción y comercialización de este tipo de producto (Reyes-Serna, 2018).

En la actualidad, el país cuenta con 88 plantas de proceso con una capacidad de 24.000 toneladas/ año para su comercialización a nivel nacional. De éstas solo cinco cuentan con la certificación sobre implementación del plan HACCP, requisito imprescindible para ingresar en los mercados internacionales. Estas últimas se encuentran localizadas en los departamentos del Huila, Tolima, Valle del Cauca, Cauca y una en el eje cafetero (Fedeagua, 2016).

Al igual que en muchos países caribeños, centro y suramericanos, la tilapia en Colombia fue introducida durante la década de los sesenta, pero sólo en la década de los ochenta su cultivo se desarrolló como una actividad comercial (Campo, 2003). En el caso del departamento del Huila, el grueso de la producción se obtiene en el embalse de Betania, donde se utilizan $36.000 \mathrm{~m}^{2}$ en espejo de agua con sistema de jaulas flotantes, y se efectúa el $70 \%$ de la producción departamental. El restante $30 \%$ de la producción de tilapia se cultiva en la mayoría 
de municipios del departamento, en sistemas de tierra-estanque, y conformado por 4.015 productores que ocupan un área de 228 hectáreas (Fedeagua, 2016).

La abundancia de recursos hídricos puede ser utilizada de manera sostenible tanto para consolidar la industria piscícola como para fines de generación hidroeléctrica (Vásquez-Salazar, Pupo-Urrutia \& Jiménez-Aguas, 2014). En cuanto al primer uso, los cultivos acuícolas en estanques artificiales y en la represa de Betania, mediante el sistema de jaulas, le han permitido al Huila convertirse en el primer productor nacional de tilapia roja, seguido por los departamentos de Tolima, Valle del Cauca y los Llanos Orientales.

La producción destinada a la exportación tiene altos estándares de calidad del producto y elevados niveles de exigencia en toda la cadena de valor, en aspectos como: la calidad de la semilla, el tiempo para alcanzar las tallas del mercado (diez meses), el capital de trabajo y la liquidez. Estos y otros factores deben tenerse en cuenta en caso de que el producto no pueda ser exportado de acuerdo a lo planeado, hecho que tiene un considerable impacto económico sobre las empresas, al ser un producto de baja demanda en el mercado nacional (Observatorio Agrocadenas Colombia, 2005).

Teniendo en cuenta el inmenso potencial de la tilapia roja, en la agenda interna del departamento del Huila se plasmó como visión de este sector: "Consolidar la cadena piscícola, posicionando al Huila como primer productor nacional de productos derivados de la acuicultura con una gestión de manejo de los recursos naturales en forma integral “(Comisión Regional de Productividad y Competitividad del Huila, 2010).

Sin embargo, la piscicultura del Huila, especialmente la producción de tilapia, en los últimos años ha sido golpeada por problemas como: alta mortalidad en la represa de Betania por sobreproducción y por la presencia de bacterias, baja producción por factores climáticos, altos costos en los insumos (comida para los animales), falta de alevinos de mojarra para la venta y abastecimiento de proyectos de engorde, poca productividad por metro cúbico y altos costos de producción, baja asequibilidad a tecnología de punta para el pequeño y mediano productor con la que pueda mejorar productividad y competitividad. Esto se une al gran desconocimiento de los productores del sector piscícola, sobre las diversas alternativas existentes en otras regiones y países que ayuden a mejorar la productividad del sector (Cámara de Comercio de Neiva, 2014). Lo anterior ha llevado a que la producción en la represa esté migrando a estanques en tierra para contrarrestar las problemáticas mencionadas, con el consiguiente incremento en los costos de producción (Cámara de Comercio de Neiva, 2013).

En vista de lo anterior, el objetivo de la investigación fue el de realizar un Estudio de Vigilancia Tecnológica e Inteligencia Competitiva sobre la tilapia roja. Esto con el fin de identificar elementos que permitan agregar valor al cultivo de la tilapia en el Huila, a través de prácticas productivas más ecológicas y sostenibles.

\section{Marco teórico y metodología}

2.1 Vigilancia tecnológica e inteligencia competitiva

Los avances tecnológicos, el crecimiento de las empresas, la innovación y generación de nuevos productos, han llevado a que las empresas busquen herramientas que les permitan sobrevivir en un mundo cada vez más competitivo. En este contexto, las organizaciones deben ser muy eficientes en la toma de decisiones, proceso que se debe apoyar en la vigilancia tecnológica e inteligencia competitiva, de tal forma que se genere una excelente dirección estratégica (Hernández-Fuentes \& Sánchez-Mojica, 2017).

Según Domínguez (2007), la Vigilancia Tecnológica, VT, es la actividad que identifica las evoluciones y novedades de la tecnología, tanto en proce- 
sos como en productos, con el fin de determinar las oportunidades y amenazas provenientes del entorno, así como las variables tecnológicas que puedan incidir en el futuro, la organización y sus procesos productivos.

El exceso de información conduce a divagar en temas de poca relevancia para las organizaciones. En este sentido, la VT se constituye en una herramienta fundamental para los gerentes ya que brinda información actualizada y oportuna, para la toma de decisiones adecuadas al contesto. Ejemplo de ello es el análisis de patentes, el cual permite identificar conocimiento de vanguardia para ser aplicado en las organizaciones, de modo que se genere innovación en los procesos productivos, incrementando la eficiencia y permitiendo la aparición de nuevos productos (Gómez-Soto, Sánchez-Toro \& Benavides-Salazar, 2017).

Este proceso se lleva a cabo indagando en bases de datos científicas para identificar los documentos de interés. Luego, a través de software especializado, se clasifica la información útil, generando un conocimiento exacto de lo que se quiere saber para poder tomar las decisiones más acertadas; es decir, se utiliza información que publican otras personas para generar mejoras competitivas en la organización (Moya-Espinosa \& Moscoso-Durán, 2017).

Luego aparece el proceso de toma de decisiones y en éste surge la Inteligencia Competitiva, IC; la cual se entiende como el proceso de obtención ética y legal, de análisis, interpretación y difusión de información y conocimiento de valor estratégico sobre el entorno competitivo (competidores actuales y potenciales), que se transmite a los responsables de la toma de decisiones en el momento oportuno (Palop \& Vicente, 2012). Es decir, luego de tener la información, el empresario debe estar en la capacidad de analizarla y comprender cuál es el objetivo que se está buscando para poder ser más competitivo en el mercado.
La IC cobra su mayor importancia en las condiciones actuales y tendencias de la economía mundial, en el que las organizaciones y sectores económicos requieren conocer no solo el entorno local y regional, si no también lo que ocurre a nivel mundial (Valdelamar-Zapata, Ramírez-Cruz, Rodríguez-Rivera \& Morales-Rubiano, 2015). Esto debido a que la apertura de los mercados ha conllevado a lo que hoy se conoce como el contexto global, para indicar que los productos y servicios deben tener la capacidad de competir en mercados tanto locales como globales.

Así mismo, la era de las telecomunicaciones hace posible el acceso rápido y mucho más fácil a la información de todo tipo (Cote-Peña, Meneses-Amaya, Arenas-Morantes \& Caballero-Pérez, 2016). Sin embargo, esa información debe depurarse de tal manera que se construya conocimiento, con el cual se hace visible la IC que permitirá una actuación prospectiva y focalizada de las organizaciones (Masbons, 2003).

Por tanto, la IC es la que le da el sentido estratégico al sector económico u organización, pudiendo afirmarse que la aplicación de la VT cobra sentido cuando la información recopilada es filtrada, clasificada y analizada para explotarla en favor del negocio; esto es, para implementar estrategias que conduzcan al fortalecimiento de la organización (Arias-Espinosa \& Moscoso-Durán, 2017). La IC ayuda en la toma de decisiones, identifica los factores que pueden afectarla y permite también que la organización se anticipe a todos los cambios estructurales y de mercado, reduciendo la incertidumbre que se puede generar al tomar una decisión a la ligera.

Usualmente se emplean los conceptos de Vigilancia Tecnológica e Inteligencia Competitiva unidos, VT/IC, por cuanto en estas dos disciplinas hay poca diferencia. Mientras que la VT pone el énfasis en la búsqueda y la obtención de información relevante para la toma de decisiones, la IC se refiere al mismo proceso, pero poniendo el énfasis en la elaboración de esta información, implicando a menudo 
la obtención de nuevas informaciones para acabar de entenderla (Rovira, 2008).

La VT/IC, para ser relevante, contempla los siguientes elementos:

i) Identificar y analizar las necesidades de información del proceso definiendo los Factores Críticos de Vigilancia, FCV.

ii) Buscar y obtener información necesaria para el seguimiento de los FCV.

iii) Evaluar y analizar la información obtenida.

iv) Difundir internamente los resultados.

v) Usar la información para la toma de decisiones.
Estas cinco fases deben adelantarse de forma continua y por ciclos, ya que frecuentemente las decisiones tomadas implican la aparición de nuevos FCV, iniciándose una nueva iteración.

\subsection{Metodología}

El tipo de investigación es cualitativa, descriptiva, no experimental y la toma de datos fue transversal. La recolección de la información se realizó mediante fuentes secundarias con los gestores de búsqueda existentes sobre publicaciones y actualizaciones del proceso de producción. La metodología del estudio de VT/IT para el proceso de producción de la tilapia roja en el departamento del Huila, implicó tres grandes fases: planeación, búsqueda y captación de la información, y análisis y tratamiento de la misma, ver Figura 1.

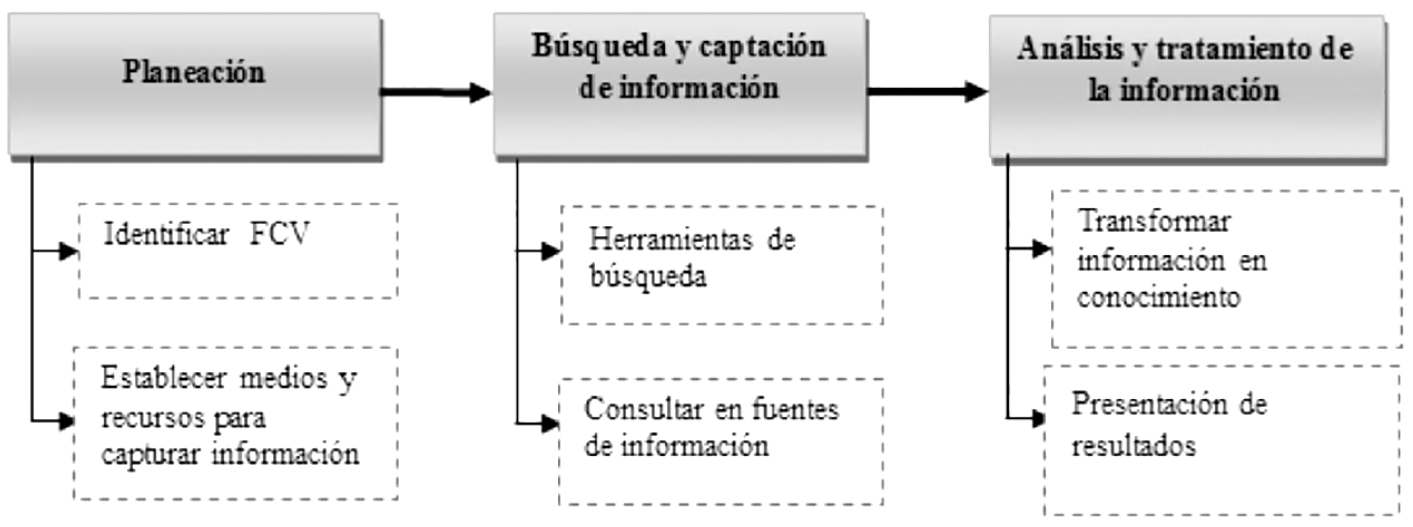

Figura 1. Metodología; Fases del estudio realizado.

La fase de planeación correspondió a la identificación de necesidades de información en el sector piscícola del Huila, específicamente en las empresas dedicadas a la producción de tilapia roja. Estos temas de interés estratégico corresponden a los FCV, que han sido definidos en el Diagnóstico de la Cadena Productiva Pesquera de Colombia, por el Ministerio de Comercio, Industria y Turismo (2002).

La fase de búsqueda y captación de información permitió adquirir la materia prima para abordar las necesidades de las empresas, en relación con innovaciones y avances a nivel de ciencia y tecnología que se están generando en cuanto a la producción de tilapia roja. Esta información debería ser conocida por los empresarios del Huila, para orientar estratégicamente sus unidades productivas. En esta fase se realizó la búsqueda de patentes relacionadas con la producción de tilapia, modelos de utilidad y diseños industriales, así como la producción científica de artículos publicados en los últimos cinco años. 
Como tercera fase se tuvo el análisis y tratamiento de la información recopilada, que enmarca lo que se conoce como IC. En este punto se transforma la información en conocimiento, que resulta vital para los propietarios y directivos de las unidades productivas piscícolas que cultivan tilapia roja en el departamento del Huila, para que tomen decisiones con un menor nivel de incertidumbre.

\section{Resultados y discusión}

\subsection{Factores críticos de vigilancia}

Los FCV resultan de las necesidades de información estratégica que en este caso tiene el sector piscícola dedicado a la producción de Tilapia en el departamento del Huila. En este punto se revisó, en primera instancia, la Agenda Interna de
Productividad y Competitividad del Huila, AIPCH. En relación a la apuesta productiva denominada: consolidar la cadena piscícola posicionando al Huila como primer productor nacional, se encontró que con la implementación de la apuesta productiva acuícola, se busca fortalecer la producción de proteína animal con destino, en primera instancia al mercado internacional y en segundo lugar al mercado nacional (Comisión Regional de productividad y Competitividad del Huila, 2010).

Adicionalmente, en el Diagnóstico de la Cadena Productiva Pesquera de Colombia (Ministerio de Comercio, Industria y Turismo, 2002), se identificaron los Factores Críticos de cada uno de los eslabones de la cadena productiva, de los cuales se seleccionaron para la vigilancia aquellos correspondientes al Eslabón de cultivo, ver tabla 1.

\begin{tabular}{ll}
\hline Área de Vigilancia & Factores críticos de Vigilancia \\
\hline & Insumos \\
& Sistemas de producción \\
& Homogeneidad de producto \\
Eslabón de cultivo dentro de la cadena productiva & Producción de Semillas \\
& Proceso de Conservación (cadena de frío) \\
& Sistema de embalaje \\
\hline
\end{tabular}

Tabla 1. Factores del eslabón de cultivo considerados para la VT.

\subsection{Hallazgos frente a publicaciones científicas}

A partir de los Factores Críticos de Vigilancia definidos en este estudio para el eslabón del cultivo dentro de la cadena productiva de la tilapia roja
(Oreochromis mossambicus), se construyó la ficha de VT mostrada en la tabla 2. En ella se establecen las palabras clave relacionadas con la temática, las fuentes de consulta y los recursos para la captura de información. 


\begin{tabular}{lll}
\hline Palabras clave & En Español & En Inglés \\
\hline $\begin{array}{l}\text { Sistemas de producción Oreo- } \\
\text { chromis mossambicus }\end{array}$ & $\begin{array}{l}\text { Production systems Oreochro- } \\
\text { mis mossambicus }\end{array}$ \\
$\begin{array}{l}\text { Homogeneidad de producto } \\
\text { Oreochromis mossambicus }\end{array}$ & $\begin{array}{l}\text { Product homogeneity Oreo- } \\
\text { chromis mossambicus }\end{array}$ \\
& $\begin{array}{l}\text { Producción de Semillas Oreo- } \\
\text { chromis mossambicus }\end{array}$ & $\begin{array}{l}\text { Seed Production Oreochromis } \\
\text { mossambicus }\end{array}$ \\
\hline Fuentes de Consulta & $\begin{array}{l}\text { Acceso a publicaciones a través de EBSCOhost, Google académi- } \\
\text { co y Scopus para consulta de artículos científicos y para consulta } \\
\text { de patentes se selecciona Google Patents e Intelligo Patentes. }\end{array}$ \\
\hline
\end{tabular}

Tabla 2. Ficha de VT para la cadena productiva de la tilapia roja.

En la tabla 3 se registra la cantidad de artículos encontrados en las bases de datos consultadas, para los tres FCV identificados en el estudio. En ella se observa que la homogeneidad del producto y los sistemas de producción, son los aspectos más tratados por los investigadores.

\begin{tabular}{llll}
\hline Factores Críticos de Vigilancia & EBSCOhost & Google Académico & Scopus \\
\hline Sistemas de Producción & 3 & - & 15 \\
Homogeneidad del producto & 2 & 3 & 18 \\
Producción de Semilla & 7 & 5 & 7 \\
Total & $\mathbf{1 2}$ & $\mathbf{8}$ & $\mathbf{4 2}$ \\
\hline
\end{tabular}

Tabla 3. Síntesis de artículos por FCV en las Bases de datos consultadas.

También se encontró a través del buscador Scopus el porcentaje de participación en los diferentes sectores, referentes a la producción de tilapia roja (Oreochromis mossambicus), ver figura 2. 


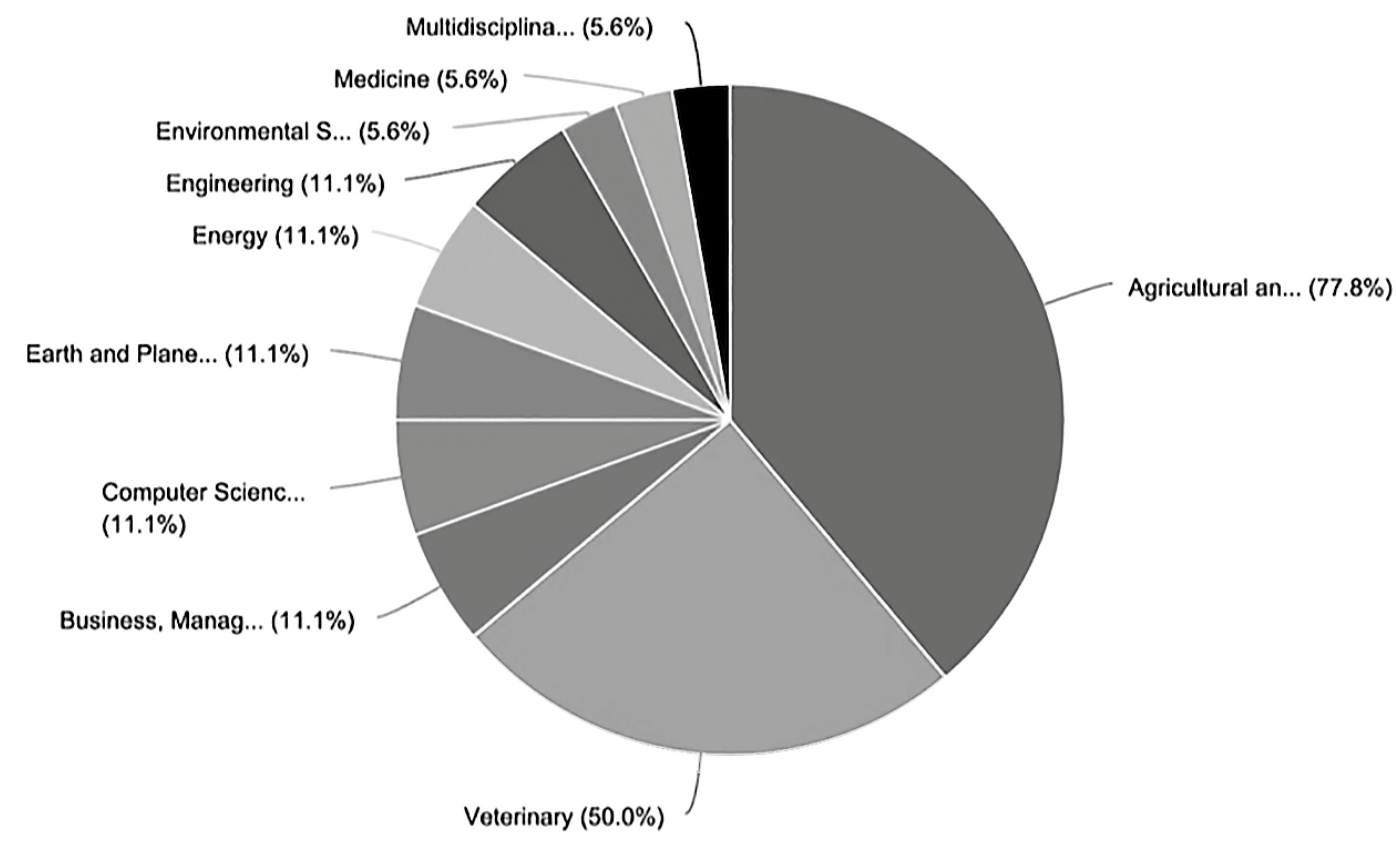

Figura 2. Temas o subáreas investigadas sobre Tilapia roja en Scopus.

La información recolectada permite reconocer los avances tecnológicos relacionados con la producción de tilapia roja, que deben ser informados a los productores piscícolas del Huila. Esto les permitirá mantener el liderazgo en un mercado altamente competitivo, que requiere la toma de decisiones acertadas para posicionar su liderazgo y participación.

\subsection{Hallazgos frente a patentes}

En la tabla 4 se presentan las patentes asociadas a la producción de tilapia roja, la cual fue organizada con base en los lineamientos de la Organización Mundial de la Propiedad Intelectual, OMPI (2017).

\begin{tabular}{|c|c|c|c|}
\hline & Campo de desarrollo de la patente & $\begin{array}{l}\text { Clasificación Inter- } \\
\text { nacional de Patentes } \\
\text { IPC }\end{array}$ & Año \\
\hline WO2015121858 & Vacuna del virus del lago para tilapia. & $\begin{array}{l}\mathrm{A} 61 \mathrm{~K} \\
\mathrm{C} 12 \mathrm{~N}\end{array}$ & 2014 \\
\hline WO2010109470 & $\begin{array}{l}\text { Formulaciones y métodos para mejorar la inmuni- } \\
\text { dad no específica y la resistencia a enfermedades } \\
\text { en tilapia. }\end{array}$ & $\mathrm{A} 01 \mathrm{~N}$ & 2009 \\
\hline WO2007148079 & $\begin{array}{l}\text { Herramienta molecular para mejorar la tolerancia } \\
\text { de la sal en un organismo. }\end{array}$ & $\begin{array}{l}\text { C07K } \\
\text { C12K }\end{array}$ & 2006 \\
\hline WO2012079427A1 & $\begin{array}{l}\text { Método de control biológico para controlar la en- } \\
\text { fermedad de Pramedia por tilapia. }\end{array}$ & $\mathrm{A} 01 \mathrm{~K}$ & 2010 \\
\hline WO2014178501 & $\begin{array}{l}\text { Composición cosmética funcional que comprende } \\
\text { hidrolizado enzimático de escamas de tilapia roja. }\end{array}$ & A61K & 2013 \\
\hline
\end{tabular}




\begin{tabular}{|c|c|c|c|}
\hline & Campo de desarrollo de la patente & $\begin{array}{l}\text { Clasificación Inter- } \\
\text { nacional de Patentes } \\
\text { IPC }\end{array}$ & Año \\
\hline WO2012129375A2 & $\begin{array}{l}\text { Vacunación para la reversión sexual de tilapia híbri- } \\
\text { da con una vacuna vibrio vulnística inactivada. }\end{array}$ & $\begin{array}{l}\mathrm{A} 61 \mathrm{~K} \\
\mathrm{C} 12 \mathrm{~N}\end{array}$ & 2011 \\
\hline WO2011006993 & $\begin{array}{l}\text { Uso de sustancias naturales como aditivos alimen- } \\
\text { tarios para animales acuáticos }\end{array}$ & A23K & 2009 \\
\hline WO2007009403 & $\begin{array}{l}\text { Poli péptidos estimulantes del crecimiento para } \\
\text { uso en peces y crustáceos }\end{array}$ & $\begin{array}{l}\text { A23K } \\
\text { C07K }\end{array}$ & 2005 \\
\hline WO2013044890A1 & $\begin{array}{l}\text { Secuencias de aminoácidos para controlar patóge- } \\
\text { nos. }\end{array}$ & $\begin{array}{l}\text { A61K } \\
\text { C07K }\end{array}$ & 2011 \\
\hline WO2008013235 & $\begin{array}{l}\text { Método de eliminación de parásitos en superficie } \\
\text { corporal de peces }\end{array}$ & $\begin{array}{l}\mathrm{A} 01 \mathrm{~N} \\
\mathrm{~A} 01 \mathrm{P} \\
\mathrm{A} 23 \mathrm{~K}\end{array}$ & 2006 \\
\hline
\end{tabular}

Tabla 4. Síntesis de Patentes y campos de desarrollo.

Se encontró que en los últimos 13 años se han producido 10 patentes registradas ante la OMPI, que, según la Clasificación Internacional de Patentes, IPC por sus siglas en inglés, abarcan los siguientes campos: ciencias médicas veterinarias; microbiología o ingeniería genética; pesca; la química orgánica, concretamente en lo referente a la preparación de alimentos para tilapia con suplementos nutricionales; microorganismos benéficos y la elaboración de vacunas. Todas estas patentes buscan mejoras en la producción de la tilapia.
3.4 Hallazgos frente a grupos de investigación y centros especializados

En la tabla 5 se indica la cantidad de proyectos desarrollados por grupos de investigación colombianos, relacionados con los FCV del estudio. Se encontró que la mayoría de proyectos están orientados hacia el campo de los Sistemas de Producción, dentro de los cuales los investigadores abordan temas como las densidades de siembra, análisis de cultivo de tilapia en jaulas y en geomembrana, manejo de la alimentación y policultivo.

\begin{tabular}{lll}
\hline Factores Críticos de Vigilancia & $\begin{array}{l}\text { Proyectos de Grupos de } \\
\text { Investigación Colombia }\end{array}$ & $\begin{array}{l}\text { Proyectos Corporación Centro de } \\
\text { desarrollo Tecnológico Piscícola } \\
\text { Surcolombiano ACUAPEZ }\end{array}$ \\
\hline Sistemas de Producción & 48 & 3 \\
Homogeneidad del producto & 6 & - \\
Producción de Semilla & 12 & 1 \\
Total & $\mathbf{6 6}$ & $\mathbf{4}$ \\
\hline
\end{tabular}

Tabla 5. Síntesis de Proyectos de los Grupos de Investigación y Centros especializados. 


\subsection{Discusión}

La información descrita anteriormente permite establecer que la tendencia en los procesos investigativos, se ha enfocado en la búsqueda de una calidad estandarizada de los elementos fisicoquímicos. En este sentido, los temas fundamentales se orientan hacia la dieta alimenticia para obtener alto contenido proteico, las densidades de siembra y evaluación del desempeño de crecimiento. En menor proporción se han adelantado investigaciones sobre mejoramiento genético y un campo que se empieza a explorar es el relacionado con subproductos de tilapia roja.
La Clasificación Internacional de Patentes, CIP, se constituye en una codificación particular uniforme de carácter universal para identificar y distinguir la actividad inventiva (OMPI, 2017); además, en la disposición de símbolos de clasificación se establecen las categorías: sección, clase, subclase y grupo. En este sentido, las patentes registradas en la OMPI asociadas a "Tilapia Roja", se ubican dentro de las secciones que corresponden a necesidades corrientes de la vida y a la química. La mayor frecuencia corresponde a los códigos A61K y A23K, como lo muestra la tabla 6.

\begin{tabular}{|c|c|c|}
\hline Sección: & A & Necesidades corrientes de la vida \\
\hline Clase: & A61 & Ciencias médicas o veterinaria; higiene \\
\hline Subclase: & A61K & Preparativos para usos médicos, dentales o propósito de baño \\
\hline \multirow[t]{9}{*}{ Grupo: } & A61K35/76 & $\begin{array}{l}\text { Que contengan materiales o productos de reacción, Con cons- } \\
\text { titución indeterminada Virus; partículas subvirales; bacteriófa- } \\
\text { gos }\end{array}$ \\
\hline & A61K39/012 & Que contengan antígenos o anticuerpos Antígenos coccidios \\
\hline & A61K8/64 & Preparaciones cosméticas o análogas \\
\hline & & $\begin{array}{l}\text { Proteínas; péptidos; Derivados o productos de Degradación } \\
\text { de los mismos }\end{array}$ \\
\hline & A61K8/66 & Preparaciones cosméticas o análogas \\
\hline & & Enzimas \\
\hline & A61K8/98 & Preparaciones cosméticas de origen animal \\
\hline & A61K38/17 & Que contienen péptidos \\
\hline & & $\begin{array}{l}\text { De animales, de seres humanos De animales, de seres huma- } \\
\text { nos }\end{array}$ \\
\hline Clase: & A23 & Alimentos o productos alimenticios; su tratamiento \\
\hline Subclase & $\mathrm{A} 23 \mathrm{~K}$ & $\begin{array}{l}\text { Materias alimentarias especialmente adaptadas a los Anima- } \\
\text { les; métodos adaptados para su producción }\end{array}$ \\
\hline Grupo: & & Información no disponible \\
\hline
\end{tabular}

Tabla 6. Identificación de patentes registradas en la CIP con mayor frecuencia.

De acuerdo con lo anterior, este tipo de patentes corresponde a: vacunas, producción de alimentos y a uso de subproductos para preparaciones de tipo cosmético, que es un nuevo campo que se está explorando en el sector de la producción piscícola con tilapia roja. Igualmente, se identifica 
que en las patentes, por la sección C, se ha trabajado en microorganismos e ingeniería genética.

También se pudo determinar que los grupos de investigación en Colombia, a través de los centros especializados y los grupos de investigación de las universidades del orden nacional, han venido liderando procesos en busca del desarrollo tecnológico de la piscicultura, especialmente del cultivo de la tilapia roja. Ejemplo de ello es Acuapez, único centro de desarrollo tecnológico reconocido por Colciencias (2018), con un acuerdo de voluntades vinculante entre los entes territoriales, Colciencias y la empresa privada.

Es importante destacar nuevos procesos investigativos que se están desarrollando en Latinoamérica, específicamente en Brasil por parte de un equipo interdisciplinario del Instituto de Apoyo al Quemado, para tratar quemaduras graves en seres humanos con la piel de la tilapia. Los investigadores destacan como ventajas de utilizar la piel de un animal acuático, las siguientes: el tener menos posibilidades de infección que con otros métodos, mayor cantidad de colágeno, se evitan dolores al paciente y mejores resultados en la cicatrización (BBC mundo, 2017).

\section{Conclusiones}

Los hallazgos del estudio de vigilancia tecnológica e inteligencia competitiva, indican la necesidad de que en Colombia se implementen nuevos proyectos de mejoramiento genético para la tilapia roja. Esto debido a que al comparar el desarrollo productivo con países como China, el incremento de la productividad y crecimiento de esta especie debería ser mucho mayor.

Igualmente, se observa una gran cantidad de investigaciones en cuanto a la producción de tilapia. Sin embargo, en Colombia se desarrollan proyectos de gran importancia pero sin continuidad en el tiempo, lo cual genera poco impacto en el sector.
Una de las grandes deficiencias en lo que tiene que ver con la producción de tilapia es el gran desconocimiento de la reproducción de semilla, aparte de haber pocos actores colombianos en esta etapa. Esta situación crea un gran vacío y deficiencia en los incrementos de productividad en el sector.

El departamento del Huila y en especial la gobernación como principal gestor, ha creado una red en alianza con otros estamentos a nivel público y privado incluyendo la academia, para generar proyectos en el sector piscícola. Inclusive existe una oficina de Vigilancia Tecnológica e Inteligencia competitiva, donde se desarrollan proyectos para el departamento y la región.

Los avances tecnológicos de la cadena productiva de la tilapia, se han desarrollado principalmente en la obtención de semillas y la etapa de ceba o engorde, dejando a un lado el procesamiento de la carne. En el Huila hay tres grandes productores quienes participan activamente en todas las etapas y exportan filete de excelente calidad, situación que ha generado un gran desequilibrio en el mercado interno.

En síntesis, se realizó un proceso de búsqueda a nivel tecnológico sobre la producción de tilapia roja, encontrándose que existen investigaciones recientes que apuntan a mejorar el desarrollo de la cadena productiva. Sin embargo, se requiere mayor conocimiento e impacto de su aplicación, ya que pueden convertirse en investigaciones de papel, sin un compromiso serio con la activación de la triple hélice: empresa privada, estado y academia.

\section{Referencias}

Amado, A. C., Córdoba-Rojas, D. F., \& Barbosa, L. S. (2015). Avances de acuicultura y pesca en Colombia I. Bogotá, Colombia: Autoridad Nacional de Acuicultura y Pesca de Colombia. 
BBC Mundo (enero 10 de 2017). El revolucionario método desarrollado en Brasil para tratar quemaduras graves con piel de tilapia. Recuperado de: http:// www.bbc.com/mundo/noticias-38558721

Cámara de comercio de Neiva (2013). Informe de Coyuntura Económica. Neiva, Colombia.

Cámara de Comercio de Neiva (2014). Implementación de una red de vigilancia tecnológica, inteligencia competitiva y prospectiva en el departamento del Huila. Neiva, Colombia.

Campo-Castillo, L. F. (2003). Tilapia roja 2006, una evolución de 22 años: de la incertidumbre al éxito. Cali, Colombia.

Colciencias (2018). Centro de Desarrollo Tecnológico Acuapez, motor de crecimiento en el Huila. Recuperado de: http://www.colciencias.gov.co/node/956

Comisión Regional de productividad y Competitividad del Huila (2010). Plan Regional de Competitividad del Huila. Neiva, Colombia.

Cote-Peña, C., Meneses-Amaya, C., Arenas-Morantes, C., \& Caballero-Pérez, D. (2016). Benchmarking entre sistemas regionales de innovación: el caso de Santander y Antioquia, Colombia. Revista de Investigación, Desarrollo e Innovación, 7 (1), 11-24. doi: http://dx.doi.org/10.19053/20278306. v7.n1.2016.4088

Domínguez, O. (2007). Gestión Tecnológica: de un enfoque tradicional a la inteligencia. Bogotá, Colombia.

FAO (2014). El estado mundial de la pesca y la acuicultura: oportunidades y desafíos. Roma, Italia.

Federación Nacional de Acuicultores de Colombia, Fedeacua. (2016). Esquemas de certificaciones de calidad para mejorar la competitividad del sector de la piscicultura continental. Bogotá, Colombia.
Gómez-Soto, J., Sánchez-Toro, Ó., \& Benavides-Salazar, X. (2017). Análisis de patentes como aproximación al diseño conceptual del proceso de obtención de jarabe de lactosuero. Revista de Investigación, Desarrollo e Innovación, 7 (2), 331353. doi: https://doi.org/10.19053/20278306. v7.n2.2017.5453

Hernández-Fuentes, S., \& Sánchez-Mojica, K. (2017). Innovación y competitividad: micro y pequeñas empresas del sector agroindustrial en Cúcuta. Revista de Investigación, Desarrollo e Innovación, 8 (1), 23-33. doi: https://doi.org/10.19053/20278306. v8.n1.2017.7368

Maspons, R. P. (2003). De la vigilancia tecnológica a la inteligencia competitiva. Cataluña, España: Icaria.

Ministerio de Agricultura y Desarrollo Rural (2007). Agenda productiva de investigación y desarrollo tecnológico para la cadena productiva de la tilapia. Bogotá, Colombia.

Ministerio de Comercio, Industria y Turismo (2002). United Nations Insustrial Development Organization. Recuperado de: http://www.unido.org/fileadmin/import/24117_DiagnsticoNacionaldeColombia.pdf

Montes-Hincapié, J. M., Vargas-Martínez, E. E., Hoyos-Concha, J. L., Palacio-Piedrahita, J. C., Acevedo-Rincón, J. F., Rojas-Fernández, G. L., \& Zartha-Sossa, J. W. (2017). Priority technologies and innovations in the fishing agribusiness by the year 2032. Foresight study through the Delphi method. Revista Lasallista de Investigación, 14 (2), 105-120. doi: https://dx.doi.org/10.22507/rli.v14n2a10

Moya-Espinosa, P., \& Moscoso-Durán, F. (2017). Vigilancia tecnológica e inteligencia competitiva en el modelo empresarial del sector hotelero colombiano. Revista de Investigación, Desarrollo e Innovación, 8 (1), 11-22. doi: https://doi. org/10.19053/20278306.v8.n1.2017.7367 
Observatorio Agrocadenas Colombia. (2005). La cadena de la piscicultura en Colombia, una mirada global de su estructura y dinámica 1991-2005. Bogotá, Colombia: Ministerio de Agricultura y DesarroIlo Rural.

Organización Mundial de la Propiedad Intelectual (2017). Clasificación Internacional de Patentes. Recuperado de: http://cip.oepm.es/pdfGuia

Palop, F, \& Vicente, J. (2012). Vigilancia Tecnológica e inteligencia Competitiva para la empresa española. Barcelona, España.

Reyes-Serna, L. D. (2018). Densidades idóneas para sistemas de policultivo de especies comerciales Tilapia Roja (Oreochromis spp.) y Carpa Roja (Ciprynus carpio) en sistemas de confinamiento artesanal en lagos artificiales en Santiago de Cali (Valle del Cauca, Colombia). Idesia (Arica), 36 (1), 73-82. doi: https://dx.doi.org/10.4067/S071834292018000100073

Rovira, C. (2008). Vigilancia tecnológica e inteligencia competitiva para SEM-SEO. Barcelona España. Recuperado de: http://www.upf.edu/hipertextnet/numero-6/vigilancia-tecnologica.html
Trochez-Gonzalez, J., Valencia, M., \& Salazar-Uribe, J. (2018). Los efectos del Tratado de Libre Comercio con Estados Unidos y los precios del maíz colombiano. Apuntes del Cenes, 37 (65), 151-172. doi: $\quad$ https://doi.org/10.19053/01203053.v37. n65.2018.5988

Valdelamar-Zapata, J. A., Ramírez-Cruz, Y. L., Rodríguez-Rivera, P. D., \& Morales-Rubiano, M. E. (2015). Capacidad innovadora: cómo fomentarla, según docentes de Ciencias Económicas e Ingeniería de la UMNG. Revista de Investigación, Desarrollo e Innovación, 6 (1), 7-14. doi: http://doi. org/10.19053/20278306.3454

Vásquez-Barajas, E., García-Torres, N., Bastos-Osorio, L., \& Lázaro-Pacheco, J. (2018). Análisis económico del sector cacaotero en Norte de Santander, Colombia y a nivel internacional. Revista de Investigación, Desarrollo e Innovación, 8 (2), 237250. doi: https://doi.org/10.19053/20278306. v8.n2.2018.7963

Vásquez-Salazar, R., Pupo-Urrutia, A., \& Jiménez-Aguas, H. (2014). Sistema energéticamente eficiente y de bajo costo para controlar la temperatura y aumentar el oxígeno en estanques de cultivo de alevines de tilapia roja. Revista Facultad de Ingeniería, 23 (36), 9-23. doi: https://doi. org/10.19053/01211129.2708 